\title{
Large scale spatial patterns in species richness of Orthoptera in the Greater London area, United Kingdom: relationships with land cover
}

\author{
By Andrew Cherrill
}

Copyright, Publisher and Additional Information:

This is the accepted manuscript of an article published in Landscape Research in 2015 by Taylor \& Francis available from:

DOI:10.1080/01426397.2014.902922

\section{A note on versions:}

The version presented here may differ from the published version or version of record; if you wish to cite this item you are advised to consult the publisher's version. 
Large scale spatial patterns in species richness of Orthoptera in the Greater London area, United Kingdom: relationships with land cover.

\section{ANDREW CHERRILL}

Crop and Environment Sciences Department, Harper Adams University, Newport, Shropshire, TF10 8NB, UK.

Email: acherrill@harper-adams.ac.uk

KEY WORDS: species richness, biodiversity, urban, agriculture, land use, gradient analysis, atlas data, remote sensing 


\section{ABSTRACT}

This paper explores species richness of insects of the Order Orthoptera along spatial gradients defined using remotely sensed land cover data for an area of 5,600 km centred on the city of London. The numbers of species within grid-squares of a national atlas, controlled for recording effort, declined along composite multivariate spatial gradients representing landscapes with increasing dominance of arable and urban land uses, yet was uncorrelated with the area of an individual land cover representing cultivated land and only weakly correlated with area of a second land cover representing urban development. Few orthopteran species reside directly within either arable crops or non-vegetated urban land covers. Thus, whilst the areas of the individual land covers are intuitively sensible (and simple) measures of agricultural and urban cover respectively, their areas do not capture ecologically relevant information about variation in the composition of the uncultivated and non-urban land cover matrices within which the species actually reside. The results illustrate the advantages of using multivariate data reduction techniques (such as the Principle Components Analysis applied here) to describe spatial gradients in the extent of agricultural and urban influence. Relatively few landscape scale studies have focussed on insects and the present study illustrates a) the potential for using the Orthoptera to explore and monitor impacts of land use via analysis of large scale spatial patterns from national species distribution atlases combined with remotely sensed land cover, and b) the importance of selecting appropriate measures of land use which incorporate information on the complex mix of land cover types utilised by the species under investigation. 


\section{Introduction}

Urbanisation and agricultural intensification are major drivers of land cover change, biodiversity loss and environmental degradation (Firbank et al., 2008; Luck et al., 2004; Gaston, 2005). Despite these changes significant numbers of species are capable of surviving and indeed thriving in highly modified environments (Luck, 2007; Niemala \& Kotze, 2009; Goddard et al., 2009), and there is a growing recognition of the potential of 'green infrastructure' (comprising networks of habitat islands, stepping-stones and linear corridors) to maintain and enhance biodiversity and human well-being (Gordon et al., 2009; Jorgensen \& Gobster, 2010). There is a parallel need to identify groups of species which can act as indicators of the impacts on biodiversity of land use at landscape and regional levels such that successes (and failures) in landscape management can be identified and monitored. A suitable candidate group of species would include widespread species that are sensitive to land use, yet include representatives that are able to persist in modified landscapes (McGeoch, 1998). In this respect, the Order Orthoptera, which includes grasshoppers, crickets and allied insects, is potentially a suitable group of species (Benton, 2012). Insects have been neglected in most large scale studies of biodiversity and land use, and particularly those focussing on urban areas (McDonnell \& Hahs, 2008; Didham et al., 2010). However, a previous study of Orthoptera across a study area of almost $10,000 \mathrm{~km}^{2}$ in southern England demonstrated a negative impact of agricultural land cover on the numbers of species present (Cherrill, 2011). Effects of urban areas were not detected, probably because towns in the study area were relatively small (Cherrill, 2010), although there is also a need to identify measures 
that adequately capture the complexity of land cover mosaics in cities (Hahs \& McDonnell, 2006). The present study builds on this previous work by a) investigating spatial variation in numbers of Orthoptera in response to land cover for an area encompassing a major city, namely London, capital of the United Kingdom, and b) explores methods of describing spatial gradients in urban development and agricultural activity from remotely sensed land cover data.

\section{Methods}

\subsection{Study area}

The study covered an area of $5,600 \mathrm{~km}^{2}$ including the City of London, Greater London, and parts of the counties of Hertfordshire, Essex, Kent, East and West Sussex, Surrey, Berkshire and Buckinghamshire (Figure 1). The area comprised 56 grid-squares, each $10 \mathrm{~km}$ by $10 \mathrm{~km}$, defined by the British national Ordnance Survey (OS) grid system. For brevity these grid-squares are henceforth referred to as $10 \mathrm{~km}$ grid-squares (with reference to their linear dimensions). The grid-squares are arranged in a rectangular block measuring $80 \mathrm{~km}$ in longitude and $70 \mathrm{~km}$ in latitude. The coordinate of the SW corner of the study area is $490 \mathrm{E} 140 \mathrm{~N}$ on the British OS grid.

\subsection{Data sources}

2.2.1. Species data. Data on the presence of species in the Order Orthoptera within each of the $5610 \mathrm{~km}$ grid-squares were taken from the atlas for Britain and Ireland published in 1997 (Haes \& Harding, 1997). Records therein are classified as pre-1970 and 1970-onwards. A total of 578 species-by-square records from 1970-1997 were extracted and used to derive the number of species per grid-square, denoted S. These records are underpinned by numerous individual observations. For some species and grid-squares there were multiple observations over the 27 year period suggesting 
variation in survey-intensity (or survey effort) between grid-squares. Number of observations per grid-square (obtained from the National Biodiversity Network www.nbn.org.uk) showed no relationship with areas of individual (or composite multivariate) land cover variables (described below) but was positively correlated with the number of species per grid-square. A curve was fitted to the relationship (using a $\log _{10}$ transformation of the number of observations to ensure conformity to model assumptions) and the residuals saved. A quadratic equation gave the best fit with number of observations explaining $36 \%$ of the variation in number of species recorded within individual grid-squares $\left(\mathrm{R}=0.60, \mathrm{~F}=14.8\right.$, d.f. ${ }_{1}=2$, d.f. $\left.2=53, \mathrm{P}<0.001\right)$. The residuals, representing the unexplained variation in number of species after the influence of survey-intensity had been removed, were saved as a new variable, denoted $S_{\text {residual }}$.

\subsubsection{Land cover data. Remote sensed land cover data was obtained from the}

Countryside Information System (CIS) (Department of the Environment 1995) with a 1990 baseline and pixel size of $25 \mathrm{~m}$. These data are derived from Landsat Thematic Mapper imagery from 1987 to 1990 (a three year window being necessary due to occasional cloud cover). Analyses within this paper assume that the CIS data represent the broad pattern of land cover across the 27 year period over which species data were obtained. Detailed descriptions of the 17 land cover types and their groundtruthing with field survey are reported elsewhere (Cherrill et al., 1994, 1995; Fuller et al., 1998).

The study area contained fifteen of the 17 CIS land cover types. Unclassified land averaged $0.27 \%(\mathrm{SD}=0.24)$, with a maximum of $1.43 \%$, within any one gridsquare. Seven land covers were each found to represent less than $1 \%$ of the total study area. These covers were Bracken, Grass heath, Dense dwarf shrub heath, Saltmarsh, 
Coastal bare ground, Sea/Estuary and Open inland water. The areas of the three heath land cover types (including Bracken) were closely correlated with each other (in pairwise correlations the minimum value of the coefficient $\mathrm{r}_{\mathrm{s}}=0.50, \mathrm{P}<0.001, \mathrm{~N}=56$ ). These land cover types were combined into a single 'Heathland' cover type for analysis. The areas of the three coastal land cover types were also closely intercorrelated (with minimum pairwise $\mathrm{r}_{\mathrm{s}}=0.99, \mathrm{P}<0.001, \mathrm{~N}=56$ ). These land cover types were combined into a single cover type called 'Coastal habitat'.

\subsection{Statistical analyses.}

The dataset of eleven land cover types was subjected to Principal Components Analysis (PCA) to identify a reduced set of major axes of spatial variation through the complex landscapes within the study area. The principal components were described in terms of the areas of the original land cover types.

Correlations with orthopteran species richness, both $\mathrm{S}$ and $\mathrm{S}_{\text {residual, }}$ were determined for a) the areas of each of the individual land cover types, b) an aggregate land cover variable called 'City' produced by summing the areas of the Suburban and Urban land cover types, and c) the principal components derived from the land cover data.

The data for species richness conformed to a normal distribution (ShapiroWilk test, $\mathrm{P}=0.53$ ), while that for areas of individual land cover types did not. In the majority of cases, application of transformations failed to convert these variables to normality. Unless otherwise stated correlation coefficients are Spearman's (denoted $\mathrm{r}_{\mathrm{s}}$ ) and use untransformed data. Plotting of relationships and curve estimation within SPSS was used to check for non-linear relationships but none were found. 


\section{Results}

\subsection{Landscape composition and gradients}

Over $75 \%$ of the study area comprised Managed grassland, Suburban and Tilled land, but there was considerable variation between grid-squares (Table 1). Urban land cover centred on squares TQ 27, 28, 37, 38, and 48 in the City of London with percentage cover in the range $32 \%-60 \%$. Suburban land cover was also high in these and adjacent grid-squares (range 14\% to 58\%) (Figure 2). Outside of Greater London, Suburban land cover was typically $<20 \%$ of individual grid-squares. Tilled land cover was the dominant land cover in parts of Essex in the north east of the study area (forming up to $66 \%$ of land cover), while other non-coastal habitats had greater cover in the south western parts of the study area. Coastal land cover types were found along the estuary of the River Thames which forms the border between Essex and Kent (in squares TQ47, 57, 67) (Figure 2).

Principal Component Analysis (PCA) identified three major composite axes through the land cover data explaining $73.8 \%$ of the total variation. Correlations between the principal components and the original land cover variables, from which they are derived, are shown in Table 2 . The first axis explained $45.0 \%$ of the variation in land cover. Increasing urban land cover is a key feature of change along this axis. The axis represents a spatial gradient from landscapes dominated by semi-natural vegetation, including Tilled, but particularly Managed and Rough grassland and Deciduous woodland to landscapes dominated by Urban and Suburban land cover (Table 3). The second axis, explaining $15.6 \%$ of variation, represents a gradient of increasing cover of Tilled land (primarily arable cropping). Along this axis landscapes are characterised by increasing areas of Tilled land and declining areas of other land cover types including Woodland, Heathland and Open Water (Table 2). The third axis 
explained $13.2 \%$ of the variation in land cover between grid squares and represents a gradient of coastal influence with increasing areas of Coastal habitat and Bare ground, while Rough grassland and Tilled land cover types show less marked increases (Table 2).

\subsection{Orthopteran species richness.}

In total twenty species were recorded in the study area over the period 1970-1997

(Figure 4). The five most widespread species were: Chorthippus brunneus, $C$. parallelus, Pholidoptera griseoaptera, Meconema thalassinum and Leptophyes punctatissima (Table 3). The mean number of species recorded per grid-square was $10.3(\mathrm{SD}=3.2)$.

3.2.1. Species richness and areas of individual land cover types. Species richness, S, was positively correlated with the areas of four relatively scarce land cover types; namely Rough Grassland, Deciduous Woodland, Coniferous Woodland and Heathland, while there was a barely non-significant positive correlation with Managed grassland (Table 4). The estimate of species richness corrected for survey-intensity, $S_{\text {residual, }}$ showed similar patterns but was also significantly negatively correlated with areas of both Suburban and City land covers (Table 4).

\subsubsection{Species richness and spatial gradients in landscape composition. Both}

measures of orthopteran species richness were negatively correlated with the first axis of spatial variation in landscape composition characterised by increasing areas of hard man-made surfaces land cover (Table 4). It is important to recognise that this spatial gradient is not simply one of increasing areas of Suburban and Urban land covers; other land cover types also increase while most decline (Table 2). The gradient is a composite multivariate mix of land covers that change from relatively rural gridsquares to those in the centre of the City of London. The influence of land cover is 
evident in the map of species-richness as the relatively low numbers of species (in the range 4 to 8 ) in grid-squares towards the centre of Greater London (Figure 3), whilst numbers are typically double elsewhere.

Species-richness was also negatively correlated with the second axis of spatial variation in landscape composition characterised primarily by increasing area of Tilled land cover (Table 4). Again it is important to recognise this axis as being a multivariate spatial gradient of interdependent land covers; albeit strongly correlated with the area of Tilled land (Table 2). Species richness appears to be responding to the overall mix of land covers rather than the area of Tilled alone. In a spatial context this gradient can be seen in terms of the low numbers of species in grid-squares in Essex and along the north and eastern fringes of the study area where Tilled land was most dominant. Here species richness was typically in the range 7 to twelve (Figure 3). The areas of both City and Tilled land covers are relatively low in the south eastern corner of the study area and here species-richness was greater than elsewhere (being in the range 12 to 17$)$.

The third axis of spatial variation in landscape composition represented increasing coastal influence. Coastal land covers were limited in distribution and extent, but there was a significant positive correlation; with raised species richness in the grid-squares where the area of Coastal land cover was greatest (i.e. TQ 48, 57 and 67) (Table 4, Figure 3).

Overall, the analysis reveals clear trends in the variation of orthopteran species-richness along three multivariate axes of spatial variation in land cover composition; a) decreasing species-richness with increasing areas of man-made land covers associated with urban and suburban land uses, b) decreasing species-richness with increased cultivation of the land, and c) increasing species-richness with 
increasing areas of semi-natural vegetation in general, and a specific increase associated with coastal landscapes.

\section{Discussion}

A large number of studies have focussed on the relationship between species richness and land use intensity; the latter typically being inferred through indices capturing the areas of man-made surfaces (e.g. buildings) and/or land in agricultural production (e.g. arable cropping). The majority of studies, as here, have focussed on spatial patterns at a single point in time rather than examining temporal change (Luck, 2007). Negative, hump-backed, and positive relationships have been reported (Luck et al., 2004). Scale of observation, as defined by area of sampling unit and extent of the study area, has proved to be an important factor in the design of studies (Pautasso, 2007). Fine-grained studies of limited spatial extent, with sample-units up to $1 \mathrm{~km}^{2}$ within regions $<10,000 \mathrm{~km}^{2}$ in area, have tended to yield negative relationships between species richness and measures of urban and agricultural land use because few species reside in small sample-units dominated by artificial habitats such as hard surfaces and buildings; thus giving a clear contrast to more species-rich sample-units dominated by semi-natural vegetation (e.g. Clergeau et al., 2006; Niemala \& Kotze, 2009). Studies with coarse grain sizes (with sample-units $>1 \mathrm{~km}^{2}$ ) and large spatial extents (> 10,000 $\mathrm{km}^{2}$ ) have sometimes yielded positive relationships probably because large human populations have historically tended to develop in regions which are both ecologically productive and species rich (Pautasso, 2007; Trammell et al., 2011). Hump-backed patterns have sometimes also been found at these scales along rural to urban gradients (e.g. Evans et al., 2007). The reasons are not fully understood 
but may reflect the observation that semi-natural habitats have been comprehensively lost in both the most intensively urbanised and farmed landscapes.

Most previous studies of invertebrates have been both fine-grained and with limited geographical extent. Perhaps, not surprisingly, in view of the general trends outlined above, these studies have typically found negative relationships between intensity of human land use and species richness (e.g. Magura et al., 2008; Marini et al., 2008; Ahrne et al., 2009; Niemala \& Kotze, 2009; Cherrill, 2010; Tothmeresz et al. 2011, Bennett \& Gratton, 2012) including in a study of the impacts of urban land cover on Orthoptera in Paris (Penone et al., 2012). The present study was also of relatively limited spatial extent $\left(5,600 \mathrm{~km}^{2}\right)$ but extends the occurrence of negative relationships within the context of a coarse-gained study (using a sample-unit of 100 $\mathrm{km}^{2}$ ) and, in doing so, also demonstrates the potential utility of data held within national insect distribution atlases typically recorded at the $10 \mathrm{~km}$ grid-square level.

A potential limitation in use of species atlas data is that recording effort (or intensity) often varies between grid-squares (Dennis \& Thomas, 2000; Petrik et al., 2010). However, as in the present study, where recording intensity can be estimated the effects can be statistically removed to reveal the remaining unexplained variation in species richness attributable to land use (and other factors). Here statistically significant negative relationships were found between both 'raw' and 'corrected' estimates of species richness and several multivariate gradients of land cover identified through Principle Components Analysis (Table 4). Species richness fell by up to $50 \%$ along spatial gradients which were characterised primarily by increasing areas of man-made surfaces and cultivated land. The observation which has the potential to be of interest to the widest audience is that these relationships were seen 
most clearly when using multivariate spatial gradients, rather than individual land covers (Table 4).

Simple measures of the intensity of human land use may not be adequate to capture species responses to their environment (Hahs \& McDonnell, 2006; McDonnell \& Hahs, 2008). Thus, as the area of 'Urban' land cover increases towards central London the areas of other land cover types also change. Critically the Orthoptera are most likely to be found in these 'other non-urban' land cover types, yet even in central London there are relatively large areas of vegetated surfaces. Indeed, urban areas often contain surprisingly large areas of vegetation (Gill et al., 2008; La Rosa \& Privitera, 2013). The changing nature of these non-urban elements along land use gradients from rural to urban may therefore be central to determining the impacts on biodiversity. Understandably, in a range of studies, characterisation of urban areas has typically used variables quantifying the man-made element (i.e. where the species are not found), rather than elements describing the intervening habitat matrix (i.e. where the species are found) (McDonnell \& Hahs, 2008). Similarly within agricultural landscapes, Orthoptera reside primarily outside of arable crops (Gardiner, 2007, 2009a; Gardiner \& Marshall, 2008) and so estimates of the area of cultivated land (i.e. Tilled land cover in this study) per se is not an adequate descriptor. In an earlier study (Cherrill, 2010, 2011) found a negative relationship between orthopteran richness and agricultural land use using the same methodology as reported here. An important conclusion of that study, which finds a direct parallel here, was that even where cultivated land cover was at its maximum there was ample uncultivated land available for Orthoptera (Figure 2). The key to understanding the impacts of urban and agricultural land uses therefore lies in unravelling the processes impacting on habitats and populations in the intervening matrices. In addition to degradation of habitat 
remnants, it is likely that processes of population fragmentation and isolation are operating within both intensively managed rural and urban landscapes (Johannesen et al., 1999; With \& Crist, 1995; Penone et al., 2012). Further research incorporating the temporal and spatial dynamics of ecological populations are required to interpret the broad spatial correlations identified by gradient analysis; a point recently emphasised by Ramalho \& Hobbs (2012).

The present study argues strongly that data reduction techniques, such as PCA, applied to multivariate remotely sensed land cover data can be a useful tool for describing complex multivariate gradients in ecological studies. The method captures variation in the 'non-urban' and 'non-arable' elements of city and rural landscapes respectively that are crucial to understanding impacts on biodiversity. Simple measures, such the areas of 'Urban' and 'Tilled' land cover, fail to capture the complexity of the change along rural to urban gradients. The study also suggests that the Order Orthoptera may make a suitable group of species for investigating these processes. The Orthoptera have a number of potential advantages as ecological indicators. They are charismatic species which are attractive to the public, relatively large, conspicuous and easily identified and include both generalists and specialists (Marshall \& Haes, 1988; Benton, 2012). The Orthoptera are sensitive to habitat modification (van Wingerden et al., 1992; Marini et al., 2008; Gardiner, 2009a), spatial configuration of habitat (Bazelet \& Samways, 2011, Benedek et al., 2011), ecological succession (Fartmann et al., 2012), climate change (Gardiner, 2009b; Wissmann et al., 2009), and chemical pollutants (Yoshimura et al., 2005). They are often the dominant herbivores in grassland ecosystems in terms of biomass and are an important food source for a range of vertebrate and invertebrate species (Cherrill \& Begon, 1989; Bock et al., 1992; Gangwere et al., 1997). Finally, in the British Isles 
there is good distribution data collected via national recording schemes (Haes \& Harding, 1997; Marshall, 2001, 2010).

\subsection{Conclusions}

Species richness of orthopterans declined along multivariate spatial gradients identified from Principle Components Analysis and defined primarily by increasing areas of urban and cultivated land covers. An advantage of using PCA is that variation in composition of the 'non-urban' and 'non-arable' matrix is taken into account in defining the gradients. Variation in the composition of the matrix appears to be fundamental in determining changes in species richness but is not adequately represented by simple univariate measures of land use intensity. The study also shows that relatively coarse presence/absence data collated at $10 \mathrm{~km}$ resolution over several decades can be used to identify major drivers of spatial biodiversity patterns when combined with remotely sensed land cover data. Further research is now required to identify the specific characteristics of the landscape matrix which are important to the species investigated. This is likely to require a fine-scale focus on dynamic temporal and spatial ecological processes related to the history of land use intensification within the study area. Finally, it is concluded that insects of the Order Orthoptera represent a suitable group on which to base further studies.

\section{Acknowledgements}

This study would not have been possible without the ongoing efforts of the many amateur and professional entomologists who have contributed to the national atlas of species distribution. Thanks are also due to the Centre for Ecology and Hydrology for provision of the Countryside Information System, Dr. Tom Pope and two anonymous referees for providing helpful feedback on the manuscript. 


\section{References}

Ahrne, K., Bengtsson, J. \& Elmqvist, T. (2009) Bumble bees (Bombus spp) along a gradient of increasing urbanisation. PLOS ONE 4(5):e5574.doi:10.1371/journal.pone.0005574.

Bazelet, C. \& Samways, M. (2011) Identifying grasshopper bioindicators for habitat quality assessment of ecological networks. Ecological Indicators, 11, pp. 1259-1269. Benedek, Z., Nagy, A., Racz, I., Jordan, F. \& Varga, Z. (2011) Landscape metrics as indicators: quantifying habitat network changes of a bush-cricket Pholidoptera transsylvanica in Hungary. Ecological Indicators, 11: 930-933.

Bennett, A. \& Gratton, C. (2012) Local and landscape scale variables impact parasitoid assemblages across an urbanisation gradient. Landscape and Urban Planning, 104, 26-33.

Benton, T. (2012) Grasshoppers and crickets. (London: New Naturalist, Harper Collins).

Bock, C., Bock, J. \& Grant, M. (1992) Effects of bird predation on grasshopper densities in an Arizona grassland. Ecology, 73, 1706-1717.

Cherrill, A. J. \& Begon, M. (1989) Predation on grasshoppers by spiders in sand dune grasslands. Entomologia experimentalis et applicata, 50, pp. 225-231.

Cherrill, A. J. (2010) Species richness of Orthoptera along gradients of agricultural intensification and urbanisation. Journal of Orthoptera Research, 19, pp. 293-301. Cherrill, A. J. (2011) Species richness of Orthoptera in agricultural landscapes. Aspects of Applied Biology, 108, pp. 73-80.

Cherrill, A. J., Lane, A. \& Fuller, R. M. (1994) The use of classified Landsat-5 Thematic Mapper imagery in the characterisation of landscape composition: a case study in Northern England. Journal of Environmental Management, 40, pp. 357-377. 
Cherrill, A. J., McClean, C., Lane, A. \& Fuller, R. M. (1995) A comparison of land cover types in an ecological field survey in northern England and a remotely sensed land cover map of Great Britain. Biological Conservation, 71, pp. 313-323.

Clergeau, P., Croci, S., Jokimaki, J., Kaisanlahti-Jokimaki, M. L., \& Dinetti, M. (2006) Avifauna homogenisation by urbanisation: analysis at different European latitudes. Biological Conservation, 127, pp. 336-344.

Dennis, R. L. H. \& Thomas, C. D. (2000) Bias in butterfly distribution maps: the influence of hotspots and recorder's home range. Journal of Insect Conservation, 4, pp. 73-77.

Department of the Environment. (1995) Countryside Information System. (London: Department of the Environment).

Didham, R., Basset, Y. \& Leather, S. R. (2010) Research needs in insect conservation and diversity. Insect Conservation and Diversity, 3, pp. 1-4.

Evans, K., Greenwood, J. \& Gaston, K. (2007) The positive correlation between avian species richness and human population density in Britain is not attributable to sampling bias. Global Ecology and Biogeography, 16, pp. 300-304.

Fartmann, T., Kramer, B. \& Stelzner, D. (2012) Orthoptera as ecological indicators for succession in steppe grassland. Ecological Indicators, 20, pp. 337-344.

Firbank, L. G., Petit, S., Smart, S., Blain, A. \& Fuller, R. J. (2008) Assessing the impacts of agricultural intensification on biodiversity: a British perspective.

Philosophical Transactions of the Royal Society B, 363, pp. 777-787.

Fuller, R. M., Groom, G. B., Barr, C. J. \& Wyatt, B. K. (1998) Countryside survey from ground, air and space: different perspectives, complementary results. Journal of Environmental Management, 54, pp. 101-126. 
Gangwere, S., Muralirangan, M. C. \& Muralirangan, M. (1997) The bionomics of grasshoppers, katydids and their kin. (Wallinford: CAB International).

Gardiner, T. (2007) Orthoptera of crossfield and headland footpaths in arable farmland. Journal of Orthoptera Research, 16, pp. 127-133.

Gardiner, T., Hill, J. \& Marshall, E. J. P. (2008) Grass field margins and Orthoptera in eastern England. Entomologist's Gazette, 59, pp. 251-257.

Gardiner, T. (2009a) Hopping back to happiness? Conserving grasshoppers on farmland. Verlag (Saarbrucken: Dr. Muller).

Gardiner, T. (2009b) Macropterism of Roesel's bushcricket Metrioptera roeselii in relation to climate change and landscape structure in eastern England. Journal of Orthoptera Research, 18, pp. 95-102.

Gaston, K. J. (2005) Biodiversity and extinction: species and people. Progress in Physical Geography, 29, pp. 239-247.

Gill, S., Handley, J., Ennos, A., Pauleit, S., Theuray, N. \& Lindley, S. (2008) Characterising the urban environment of UK cities and towns: A template for landscape planning. Landscape and Urban Planning, 87, pp. 210-222.

Goddard, M., Dougill, A. \& Benton, T. G. (2009) Scaling up from gardens: biodiversity conservation in urban environments. Trends in Ecology and Evolution, 25, pp. 90-98.

Gordon, A., Simondson, D., White, M., Moilanen, A. \& Bekessy, S. (2009) Integrating conservation planning and landuse planning in urban landscapes. Landscape and Urban Planning, 91, pp. 183-194.

Haes, E. C. M. \& Harding, P.T. (1997) Atlas of grasshoppers, crickets and allied insects in Britain and Ireland. (London: The Stationary Office). 
Hahs, A. \& McDonnell, M. (2006) Selecting independent measures to quantify Melbourne's urban-rural gradient. Landscape and Urban Planning, 78, pp. 435-448. Johannesen, J., Samietz, J., Wallaschek, M., Seitz, A. \& Veitch, M. (1999) Patch connectivity and genetic variation in two congeneric grasshopper species with different habitat preferences. Journal of Insect Conservation, 3, pp. 201-209. Jorgensen, A. \& Gobster, P. (2010) Shades of green: Measuring the ecology of urban green space in the context of human well-being. Nature and Culture, 5, pp. 338-363. La Rosa, D. \& Privitera, R. (2013) Characterization of non-urbanized areas for landuse planning of agricultural and green infrastructure in urban contexts. Landscape and Urban Planning, 109, pp. 94-106.

Luck, G. W., Ricketts, T. H., Daily, G. C. \& Imhoff, M. (2004) Alleviating spatial conflict between people and biodiversity. Proceedings of the National Academy of Sciences, 101, pp. 182-186.

Luck, G. W. (2007) A review of the relationships between human population density and biodiversity. Biological Reviews, 82, pp. 607-645.

Magura, T., Tothmeresz, B., \& Molnar, T. (2008) A species-level comparison of occurrence patterns in carabids along an urbanisation gradient. Landscape and Urban Planning, 86, pp. 134-140.

Marini, L., Fontana, P., Scotton, M. \& Klimek, S. (2008) Vascular plant and Orthoptera diversity in relation to grassland management and landscape composition in the European Alps. Journal of Applied Ecology, 45, pp. 361-370.

Marshall, J. A. (2001) Grasshoppers, crickets and allied insects, in D. L. Hawksworth (Ed.). The changing wildlife of Great Britain and Ireland. (London: Taylor \& Francis).

Marshall, J. A. (2010) Grasshoppers, crickets and allied insects, in N. Maclean (Ed.). 
Silent summer. The state of wildlife in Britain and Ireland. (Cambridge: Cambridge University Press).

Marshall, J. A. \& Haes, E. C. M. (1988) Grasshoppers and allied insects of Great Britain and Ireland. (Colchester: Harley Books).

McDonnell, M. J. \& Hahs, A. K. (2008) The use of gradient analysis studies in advancing our understanding of the ecology of urbanizing landscapes: current status and future directions. Landscape Ecology, 23, pp. 1143-1155.

McGeoch, M. (1998) The selection, testing and application of terrestrial insects as bioindicators. Biological Reviews, 73, pp. 181-201.

Niemala, J. \& Kotze, D. J. (2009) Carabid beetle assemblages along urban to rural gradients. a review. Landscape and Urban Planning, 92, pp. 65-71.

Pautasso, M. (2007) Scale dependence of the correlation between human population presence and vertebrate and plant species richness. Ecology Letters, 10, pp. 16-24. Penone, C., Kerbiriou, C., Julien, J.-F., Julliard, R., Machon, N. \& Le Viol, I. (2012) Urbanisation effect on Orthoptera: which scale matters? Insect Conservation and Diversity, 6, pp. 319-327.

Petrik, P., Pergl, J. \& Wild, J. (2010) Recording effort biases the species richness cited in plant distribution atlases. Perspectives in Plant Ecology, Evolution and Systematics, 12, 57-65.

Ramalho, C. \& Hobbs, R. (2012) Time for a change: dynamic urban ecology. Trends in Ecology and Evolution, 27, pp. 179-188.

Tothmeresz, B., Mathe, I., Balazs, E., \& Magura, T. (2011) Responses of carabid beetles to urbanization in Transylvania (Romania). Landscape and Urban Planning, 101, pp. 330-337. 
Trammell, E. J., Weisberg, P. \& Bassett, S. (2011) Avian response to urbanisation in the arid riparian context of Reno, USA. Landscape and Urban Planning, 102, pp. 93101.

van Wingerden, W. K. R. E., van Kreveld, A. R. \& Bongers, W. (1992) Analysis of species composition and abundance of grasshoppers (Orthoptera, Acrididae) in natural and fertilised grasslands. Journal of Applied Entomology, 113, pp. 138-152.

Wissmann, J., Schielzeth, H. \& Fartmann, T. (2009) Landscape-scale expansion of Roesel's bush-cricket Metrioptera roeselii at the north western range limit in central Europe (Orthoptera: Tettigoniidae). Entomologia Generalis, 31, pp. 317-326.

With, K. A. \& Crist, T. O. (1995) Critical thresholds in species' responses to landscape structure. Ecology, 76, pp. 2446-2459. Yoshimura, H., Endoh, Y. \& Harada, K. (2005) Gryllus bimaculatus: A possible bioindicator organism for detection of chemical pollutants in terrestrial systems. Ecological Indicators, 5, pp. 181-188. 


\section{Figure legends}

Figure 1. The study area a) $10 \mathrm{~km}$ by $10 \mathrm{~km}$ grid-squares of the British Ordnance Survey national grid (with grid lines for $500 \mathrm{~km}$ East and $200 \mathrm{~km}$ North in bold), and b) sketch map of administrative boundaries. The two unlabelled areas at the southern boundary of the study area lie within the counties of East Sussex and West Sussex. (Abbreviations: Berks $=$ Berkshire; Bucks $=$ Buckinghamshire $)$.

Figure 2. The per cent area of six remotely sensed land covers within each 10 gridsquare within the study area.

Figure 3. The number of species of Orthoptera recorded from each $10 \mathrm{~km}$ grid-square within the study area. 
Figure 1.

a) $10 \mathrm{~km}$ grid-squares

\begin{tabular}{|c|c|c|c|c|c|c|c|}
\hline SP & TL & TL & TL & TL & TL & TL & TL \\
90 & 00 & 10 & 20 & 30 & 40 & 50 & 60 \\
\hline SU & TQ & TQ & TQ & TQ & TQ & TQ & TQ \\
99 & 09 & 19 & 29 & 39 & 49 & 59 & 69 \\
\hline SU & TQ & TQ & TQ & TQ & TQ & TQ & TQ \\
98 & 08 & 18 & 28 & 38 & 48 & 58 & 68 \\
\hline SU & TQ & TQ & TQ & TQ & TQ & TQ & TQ \\
97 & 07 & 17 & 27 & 37 & 47 & 57 & 67 \\
\hline SU & TQ & TQ & TQ & TQ & TQ & TQ & TQ \\
96 & 06 & 16 & 26 & 36 & 46 & 56 & 66 \\
\hline SU & TQ & TQ & TQ & TQ & TQ & TQ & TQ \\
95 & 05 & 15 & 25 & 35 & 45 & 55 & 65 \\
\hline SU & TQ & TQ & TQ & TQ & TQ & TQ & TQ \\
94 & 04 & 14 & 24 & 34 & 44 & 54 & 64 \\
\hline
\end{tabular}

b) Sketch map of administrative boundaries

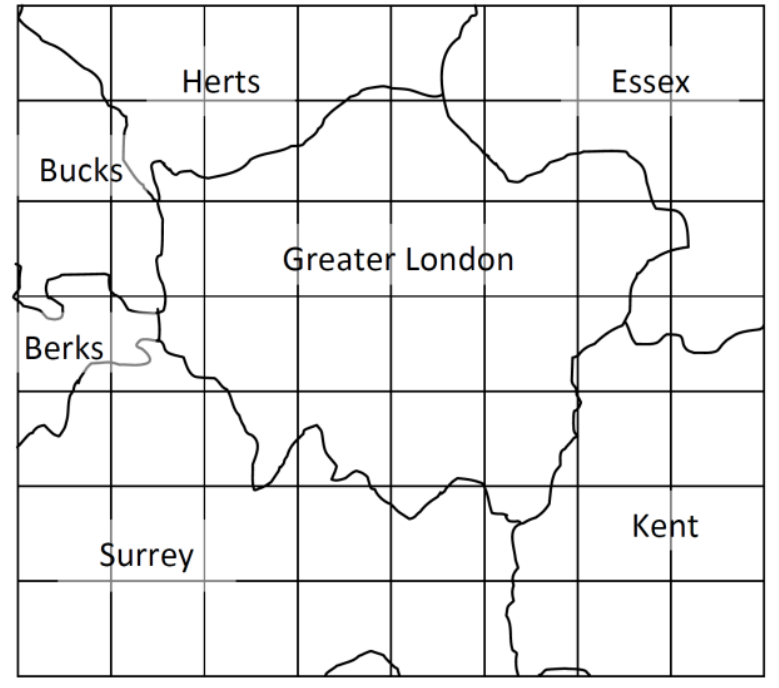


Figure 2.

a) Urban

\begin{tabular}{|c|c|c|c|c|c|c|c|}
\hline 1 & 3 & 4 & 2 & 4 & 2 & 1 & 1 \\
\hline 1 & 2 & 6 & 8 & 20 & 4 & 3 & 1 \\
\hline 3 & 4 & 14 & 43 & 60 & 32 & 9 & 3 \\
\hline 3 & 8 & 15 & 43 & 45 & 16 & 12 & 10 \\
\hline 1 & 4 & 7 & 9 & 16 & 4 & 2 & 1 \\
\hline 2 & 2 & 1 & 2 & 2 & 1 & 2 & 1 \\
\hline 2 & 1 & 1 & 2 & 0 & 0 & 2 & 1 \\
\hline
\end{tabular}

c) Tilled

\begin{tabular}{|c|c|c|c|c|c|c|c|}
\hline 29 & 30 & 29 & 28 & 20 & 43 & 66 & 58 \\
\hline 22 & 19 & 13 & 9 & 5 & 22 & 34 & 49 \\
\hline 15 & 13 & 0 & 0 & 0 & 3 & 22 & 46 \\
\hline 19 & 16 & 3 & 0 & 0 & 2 & 17 & 28 \\
\hline 14 & 18 & 10 & 5 & 7 & 19 & 34 & 31 \\
\hline 15 & 23 & 16 & 18 & 18 & 20 & 21 & 23 \\
\hline 17 & 10 & 13 & 13 & 18 & 16 & 17 & 25 \\
\hline
\end{tabular}

e) Deciduous Woodland

\begin{tabular}{|c|c|c|c|c|c|c|c|}
\hline 10 & 7 & 7 & 13 & 13 & 9 & 2 & 5 \\
\hline 15 & 13 & 7 & 6 & 5 & 15 & 7 & 7 \\
\hline 16 & 11 & 1 & 3 & 1 & 1 & 1 & 3 \\
\hline 11 & 2 & 3 & 4 & 2 & 6 & 3 & 1 \\
\hline 18 & 11 & 10 & 3 & 8 & 13 & 11 & 16 \\
\hline 19 & 13 & 22 & 14 & 17 & 16 & 15 & 13 \\
\hline 16 & 19 & 22 & 8 & 8 & 10 & 11 & 9 \\
\hline
\end{tabular}

b) Suburban

\begin{tabular}{|c|c|c|c|c|c|c|c|}
\hline 13 & 20 & 23 & 15 & 17 & 14 & 9 & 9 \\
\hline 13 & 14 & 33 & 37 & 43 & 22 & 19 & 13 \\
\hline 18 & 22 & 58 & 39 & 26 & 39 & 32 & 17 \\
\hline 16 & 28 & 47 & 32 & 38 & 49 & 24 & 23 \\
\hline 9 & 18 & 30 & 51 & 42 & 29 & 14 & 11 \\
\hline 9 & 5 & 5 & 10 & 5 & 4 & 9 & 9 \\
\hline
\end{tabular}

d) Managed Grass

\begin{tabular}{|c|c|c|c|c|c|c|c|}
\hline 43 & 37 & 31 & 37 & 37 & 28 & 19 & 23 \\
\hline 43 & 45 & 36 & 38 & 22 & 34 & 33 & 27 \\
\hline 41 & 43 & 23 & 11 & 7 & 16 & 29 & 25 \\
\hline 44 & 26 & 25 & 16 & 12 & 22 & 23 & 18 \\
\hline 40 & 36 & 35 & 29 & 25 & 32 & 35 & 34 \\
\hline 45 & 44 & 44 & 46 & 47 & 49 & 47 & 44 \\
\hline 45 & 54 & 48 & 61 & 64 & 64 & 56 & 50 \\
\hline
\end{tabular}

f) Coastal habitats

\begin{tabular}{|c|c|c|c|c|c|c|c|}
\hline 0 & 0 & 0 & 0 & 0 & 0 & 0 & 0 \\
\hline 0 & 0 & 0 & 0 & 0 & 0 & 0 & 0 \\
\hline 0 & 0 & 0 & 0 & 0 & 5 & 1 & 0 \\
\hline 0 & 0 & 0 & 0 & 0 & 2 & 11 & 13 \\
\hline 0 & 0 & 0 & 0 & 0 & 0 & 0 & 0 \\
\hline 0 & 0 & 0 & 0 & 0 & 0 & 0 & 0 \\
\hline 0 & 0 & 0 & 0 & 0 & 0 & 0 & 0 \\
\hline
\end{tabular}


Figure 3.

a) Number of species

\begin{tabular}{|c|c|c|c|c|c|c|c|}
\hline 9 & 10 & 12 & 12 & 12 & 9 & 7 & 8 \\
\hline 7 & 13 & 9 & 10 & 10 & 11 & 10 & 9 \\
\hline 13 & 10 & 7 & 4 & 7 & 12 & 11 & 9 \\
\hline 11 & 14 & 13 & 8 & 7 & 8 & 12 & 12 \\
\hline 16 & 14 & 15 & 9 & 10 & 2 & 7 & 9 \\
\hline 14 & 14 & 15 & 15 & 13 & 6 & 8 & 8 \\
\hline 17 & 15 & 12 & 13 & 12 & 7 & 6 & 5 \\
\hline
\end{tabular}




\section{Table legends}

Table 1. The areas $(\%)$ of remotely sensed land covers within $10 \mathrm{~km}$ grid-squares $(\mathrm{n}=56)$ within the study area $(\mathrm{SD}=$ Standard Deviation $)$.

Table 2. Correlations between the Principal Components from PCA of land cover data and the area of individual land cover types $(r=$ Pearson's correlation coefficient derived from PCA; values in bold are statistically significant, $\mathrm{P}<0.05, \mathrm{n}=56$ in all cases).

Table 3. The per cent of $10 \mathrm{~km}$ grid-squares $(n=56)$ occupied by each species in the study area.

Table 4. Correlations between measures of the species ( $S$ and $\left.S_{\text {residual }}\right)$ in each gridsquare and a) the area of each individual land cover type, and b) the Principal Components derived from PCA of land cover data $\left(\mathrm{r}_{\mathrm{s}}=\right.$ Spearman's correlation coefficient, $\mathrm{n}=56$ in all cases). 
Table 1.

\begin{tabular}{lcccc}
\hline Land cover & Mean & SD & Minimum & Maximum \\
\hline Urban & 7.90 & 12.70 & 0.20 & 59.67 \\
Suburban & 20.80 & 13.50 & 3.99 & 58.26 \\
City (Urban + Suburban) & 28.74 & 23.29 & 4.25 & 85.97 \\
Tilled & 19.20 & 14.00 & 0.00 & 66.38 \\
Managed grassland & 35.30 & 13.10 & 7.04 & 64.00 \\
Rough grassland & 2.70 & 1.00 & 0.47 & 4.90 \\
Deciduous woodland & 9.50 & 5.80 & 0.76 & 22.08 \\
Coniferous woodland & 1.10 & 1.75 & 0.01 & 8.95 \\
Heathland & 0.86 & 0.95 & 0.03 & 6.08 \\
Bare ground & 1.00 & 0.93 & 0.18 & 5.14 \\
Open water & 1.00 & 0.93 & 0.00 & 9.53 \\
Coastal & 0.58 & 2.37 & 0.00 & 13.39 \\
\hline
\end{tabular}


Table 2.

\begin{tabular}{lccc}
\hline & \multicolumn{3}{c}{ Principal Components } \\
& I & II & III \\
\hline Urban & $\mathbf{0 . 7 9}$ & $\mathbf{- 0 . 2 9}$ & -0.23 \\
Suburban & $\mathbf{0 . 8 2}$ & -0.17 & -0.26 \\
Tilled & $\mathbf{- 0 . 3 6}$ & $\mathbf{0 . 7 1}$ & $\mathbf{0 . 3 6}$ \\
Managed grassland & $\mathbf{- 0 . 8 1}$ & 0.01 & -0.08 \\
Rough grassland & $\mathbf{- 0 . 8 7}$ & -0.09 & $\mathbf{0 . 3 8}$ \\
Deciduous woodland & $\mathbf{- 0 . 8 6}$ & -0.24 & -0.16 \\
Coniferous woodland & $\mathbf{- 0 . 6 2}$ & $\mathbf{- 0 . 5 9}$ & 0.00 \\
Heathland & $\mathbf{- 0 . 5 6}$ & $\mathbf{- 0 . 6 3}$ & 0.16 \\
Bare ground & $\mathbf{0 . 6 5}$ & $\mathbf{- 0 . 2 8}$ & $\mathbf{0 . 6 3}$ \\
Open water & $\mathbf{0 . 4 3}$ & $\mathbf{- 0 . 4 4}$ & 0.23 \\
Coastal & $\mathbf{0 . 3 1}$ & 0.01 & $\mathbf{0 . 7 4}$ \\
\hline
\end{tabular}


Table 3.

\begin{tabular}{lc}
\hline Species & \% grid-squares \\
\hline Meconema thalassinum (Degeer) & 83.9 \\
Tettigonia viridissima (L.) & 12.5 \\
Pholidoptera griseoaptera (Degeer) & 85.7 \\
Metrioptera brachyptera (L.) & 19.6 \\
Metrioptera roeselii (Hagenbach) & 80.4 \\
Conocephalus discolor (Thunberg) & 41.1 \\
Conocephalus dorsalis (Latreille) & 42.9 \\
Leptophyes punctatissima (Bosc) & 82.1 \\
Acheta domesticus (L.) & 33.9 \\
Gryllotalpa gryllotalpa (L.) & 1.8 \\
Tetrix subulata (L.) & 58.9 \\
Tetrix undulata Sowerby & 58.9 \\
Omocestus rufipes Zett. & 14.3 \\
Omocestus viridulus (L.) & 76.8 \\
Myrmeleotetix maculatus (Thunberg) & 28.6 \\
Gomphocerippus rufipes (L.) & 16.1 \\
Chorthippus albomarginatus (Degeer) & 67.9 \\
Chorthippus brunneus (Thunberg) & 96.4 \\
Chorthippus parallelus (Zetterstedt) & 96.4 \\
Stenobothrus lineatus (Panzer) & 33.9 \\
\hline
\end{tabular}


Table 4.

\begin{tabular}{lccccc}
\hline Variables correlated with species richness & \multicolumn{2}{c}{$\mathrm{S}$} & \multicolumn{2}{c}{ S $_{\text {residual }}$} \\
& $\mathrm{r}_{\mathrm{s}}$ & $\mathrm{P}$ & $\mathrm{r}_{\mathrm{s}}$ & $\mathrm{P}$ \\
\hline a) Land cover types & & & & \\
Urban & -0.07 & 0.59 & -0.25 & 0.07 \\
Suburban & -0.06 & 0.65 & -0.27 & 0.05 \\
City (Urban + Suburban) & -0.09 & 0.51 & -0.30 & 0.02 \\
Tilled & -0.10 & 0.47 & 0.01 & 0.94 \\
Managed grassland & 0.25 & 0.07 & 0.25 & 0.07 \\
Rough grassland & 0.36 & $<0.01$ & 0.44 & $<0.001$ \\
Deciduous woodland & 0.32 & $<0.02$ & 0.22 & 0.10 \\
Coniferous woodland & 0.45 & $<0.001$ & 0.41 & $<0.001$ \\
Heathland & 0.52 & $<0.001$ & 0.47 & $<0.001$ \\
Bare ground & 0.03 & 0.84 & -0.11 & 0.43 \\
Open water & 0.13 & 0.34 & -0.07 & 0.61 \\
Coastal & 0.07 & 0.62 & -0.11 & 0.44 \\
b) Principle Components & & & & \\
PC I & -0.27 & 0.04 & -0.34 & 0.01 \\
PC II & -0.41 & $<0.001$ & -0.27 & 0.05 \\
PC III & 0.30 & 0.03 & 0.40 & $<0.001$ \\
\hline
\end{tabular}

